\title{
TURNING POINT Sarah Aciego
}

Sarah Aciego, a glaciochemist who has pioneered isotope dating of ice cores at the University of Michigan in Ann Arbor, won a five-year US\$875,000 grant from the David and Lucile Packard Foundation in Los Altos, California, on 15 October.

\section{How did events at university help to set you} on your current path?

I ended up as a geology major based in the engineering school, and therefore took chemistry, physics and calculus, learning skills that facilitated my exposure to isotope work. I didn't have much money, so I needed a work-study job. I distributed flyers advertising my calculus and computer-programming skills around the department, and was hired to write programs to process isotope data looking at dust inputs and silica cycling in soil ecosystems.

\section{How did your work with isotopes continue?}

I applied to a number of graduate schools, and came to work with an isotope chemist who was using radiogenic isotopes to examine volcanic processes. But a change to the $\mathrm{PhD}$ requirements the year I arrived meant that I had to present and defend two possible thesis projects during qualifying exams, so I had to find a second adviser and develop an alternate project, working with a glaciologist who was using stable isotopes to date ice sheets in Antarctica. I was so interested in both topics that I did two $\mathrm{PhD}$ projects.

\section{How did that affect your opportunities?}

There is a pretty big divide between the radioand stable-isotope research communities. But my combined efforts made me realize where my expertise could make a difference. Dating the deepest ice had proved nearly impossible using conventional methods, so I wanted to use a radiometric isotope technique to date ice using dust. I did that for my postdoc at the Swiss Federal Institute of Technology in Zurich, where a talented mass spectrometrist and engineer, Heinrich Baur, developed both a device called a nanoscale that measures nanogram variations in mass, and a technique to measure the weight of dust and the weight of the gas absorbed on the dust.

You started at Michigan in 2010. Were you surprised by the generous support you received despite the economic downturn?

Yes. I interviewed at six places over two years and didn't think I had a chance in hell of anyone buying me the equipment I needed.

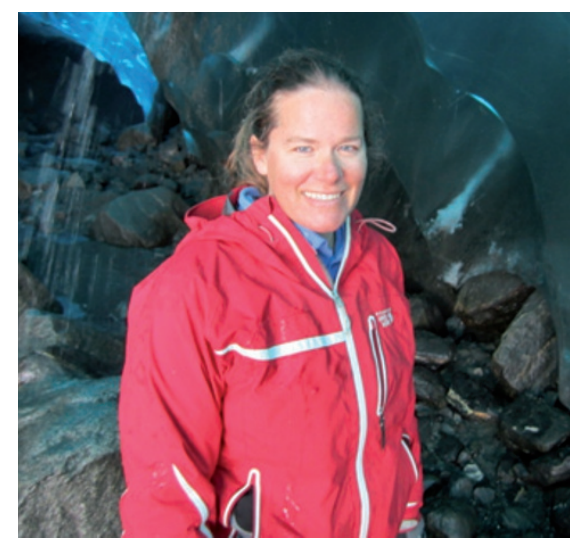

Luckily, the University of Michigan realized the value of the machines and clean lab facilities necessary to run the kind of experiments I wanted to do. And the US National Science Foundation partially funded me to get one of the $\$ 200,000$ nanoscales developed in Zurich. In return, I try to serve as a resource to the field and to my students, and try to bring what I do into the classroom and to the public.

What does the Packard award allow you to do? The Packard grant is huge because I can redirect some of the money, which is unrestricted, to my projects that are having a harder time getting funded. It is also helpful because the fieldwork for this research is so expensive. I have proved that my methods work in Antarctica, but this funding allows me to collect samples across Greenland to see if it works there as well. If it does, it will provide a much-needed comparison to clarify the impacts of climate change on sea-level rise. We will learn something - although it may not be what we set out to find.

Do you network naturally or out of necessity? Necessity. I have learned that you have to put yourself out there and create a broad base of support from your community to garner recognition. A lot of those interactions happen during social events after conference talks. One of the nicest things that I read in reviews of my proposals, even those that have been rejected, is that I'm a rising star in the field and know what I'm doing. These comments are from people I haven't worked with directly - they have seen me in some public forum. I impress on my students that we go to meetings to advertise not only the science, but also our capabilities.

INTERVIEW BY VIRGINIA GEWIN 